\title{
Improving traditional methods of teaching chemistry
}

\author{
Usmonova Lola Mallaevna
}

\begin{abstract}
This research corresponds to the priority of the development of science and technology of the republic. "Spiritual and moral, cultural development of a democratic and legal society, the formation of an innovative economy." The research is carried out within the framework of the research plan of the Navoi State Pedagogical Institute. The main results of the study will be tested in the activities of pedagogical institutes, including students of Navoi State Pedagogical Institute, as well as in the 1st academic lyceum in Navoi and the 2nd academic lyceum under Navoi State Mining Institute.
\end{abstract}

Keywords: modernization, methodological framework, traditional way of teaching.

\section{Introduction}

Particular attention is paid to the practice of modernization of chemistry education in the world, the introduction of person-centered technologies and modern methods, improving the methodological framework for the development of chemistry teaching methods in accordance with modern development trends. Improving its content through the introduction of person-centered strategies in the teaching of chemistry in the United States, Japan, Germany, China, France, improving the quality of students' knowledge, finding and implementing new ideas in the formation of special scientific competencies, and as a result, the work on training of mature specialists will be of great importance.

Today, effective research is being conducted internationally to improve the content of teaching chemistry, the introduction of pedagogical and information technologies in the teaching process, the use of person-centered educational technology, the creation of modern teaching aids aimed at developing students' intellectual and creative abilities. In improving the content of teaching chemistry, it is necessary to apply scientific developments in the educational process on the theoretical and methodological basis.

\section{Main part}

In particular, on the recommendation of scientists from Brandeu University (America), Albert-LudwigsUniversity (Germany), Mie University (Japan), Rostov State Pedagogical University, Volgograd State University of Social Pedagogy (Russia) to improve the quality of education, improve the content of teaching chemistry, the application of scientific developments in the theoretical, methodological and methodological bases of the educational process is of great importance.

Chemistry teaching methodology, like other sciences, has its own history. According to the definition of the Chemistry Teaching Methodology (CTM), chemistry came into being and evolved at the same time as its emergence and development. A. Lavoisier, D. Dalton, S. Cannitsaro and other scientists have made a significant contribution to the development of methodology, engaging not only in scientific but also in pedagogical activities.

The methodology of teaching chemistry as a scientific science appeared in the middle of the XIX century. M.V. Lomonosov, D.I. Mendeleev and A.M. Butlerov played a special role in creating the scientific basis of chemistry teaching methods. M.V. Lomonosov was the first in the world to create a work entitled "Introduction to Chinese Physics", which defined the tasks, content, methods of teaching physical chemistry; compiled a special program of lectures and lectured to university students on the basis of this program. Mendeleev was a scientist who showed great skill in the field of science, his skill was to discover the periodic law and the periodic table of chemical elements. After D.I. Mendeleev created his textbook "Fundamentals of Chemistry", he began to study the elements in groups of the periodic table. This method is still used in the teaching of inorganic chemistry. In the works of D.I. Mendeleev, the goals and objectives of teaching chemistry are clearly stated. "Chemistry must be closely connected with practical life," wrote Mendeleev.

The scientist A.M. Butlerov, who founded the theory of the chemical structure of substances, in his works, especially in his famous manuals "Introduction to the perfect study of organic chemistry", "Basic concepts of chemistry" very clearly described a number of his methodological guidelines.

During the Soviet era, the methodology of teaching chemistry became part of pedagogy. This period is associated with the names of V.N.Verkhovsky, S.I.Sazonov, S.G.Krapivin, P.P.Lebedev, D.I.Kiryushkin, P.A.Gloriozov and many other scientists, who at this time did not later justify themselves. "Project method", "Dalton-plan", "brigade method" were widely developed.

Well-known scientists of the republic, academicians H.U.Usmanov, O.S.Sodikov, S.Yunusov, Sh.T.Talipov also created their schools and made a significant contribution to the development of methodology.

At present, the country is undergoing major reforms in the field of education, there are dramatic changes in the system of secondary education. New educational institutions are opening. They differ from each other in their curricula, their in-depth study of certain subjects, as well as chemistry, and their focused teaching of students. 
The Action Strategy for the further development of the Republic of Uzbekistan identifies as a priority "in-depth study of important and demanding disciplines such as chemistry, mathematics, physics, biology, computer science." In this regard, the methodological structure of teaching chemistry, the level of quality of knowledge acquisition of students, organizational and pedagogical stages of improving the content of teaching chemistry, enrichment of information and methodological support for independent work are important.

Resolution of the President of the Republic of Uzbekistan dated September 5, 2018 No PP-3931 "On measures to introduce new principles of governance in the public education system", January 25, 2018 "On measures to radically improve the system of general secondary, secondary special and vocational education PF5313 of September 5, 2018, PF-5538 of September 5, 2018 "On additional measures to improve the management system of public education" and April 29, 2019 "On the Concept of development of the public education system of the Republic of Uzbekistan until 2030" This dissertation to some extent serves in the implementation of the tasks set out in other regulations related to this field, decrees PF-5712. Because the radical improvement of the system of general secondary, secondary special and vocational education is directly related to the development of methodological skills of future teachers, the level of ability to demonstrate skills.

This research will serve to some extent in the implementation of the tasks set out in the Decree of the President of the Republic of Uzbekistan dated February 7, 2017 No PF-4947 "On the Strategy of further development of the Republic of Uzbekistan" and other regulations related to this activity. The purpose of the study is to improve the quality of production of specialists in the field of chemistry. The object of research is the process of teaching chemistry in higher education. The subject of research is the development of methods of teaching chemistry in higher education.

The organization and management of the process of development of methods of teaching chemistry in higher education will be effective with the following:

1) to reveal the essence of the development of methods of teaching chemistry and its application in the process of teaching chemistry in higher education institutions;

2) to implement a systematic approach to planning and managing the process of developing students' intellectual abilities;

3) to take into account the expansion of the scope of pedagogical interaction "student - teacher specialist" in the organization of the development of methods of teaching chemistry;

4) to include in the requirements of learning outcomes the disclosure of the level of methodological training of students;

5) to select methods and tools that activate the process of developing chemistry teaching methods.

\section{The purpose of the study}

Its hypothesis and subject matter were the basis for defining the research objectives:

1) Analysis of philosophical, social, psychological, pedagogical, methodological literature and teaching practices in order to determine the approach to solving these problems;

2) Disclosure of methodological opportunities that stimulate the development of intellectual potential of students in the teaching of chemistry;

3) development of a methodical system model of the integrated process of intellectual development in chemistry teaching, taking into account the expansion of the scope of "pedagogical interaction";

4) Development of a methodology for organizing a holistic process of developing the intellectual potential of students, taking into account the mastery of students with different worldviews and areas of thinking;

5) Describe a system of developmental tasks and tools based on the expansion of the system of chemical knowledge, including a system of research workshops that include a historical experiment;

6) Selection of content for the curriculum, which develops the potential of the field of chemistry;

7) Checking the effectiveness of the methodological system used by students based on the results of their research activities.

A chemistry teacher equips students with the basics of chemistry, develops their abilities, forms in them a scientific worldview. To do this, it is necessary to be able to apply the acquired knowledge and skills in the field of pedagogy, psychology, chemistry and its teaching methods to solve a specific educational task. The professional requirements for a teacher determine the methodology of teaching chemistry. In this way, the theory that has been inherent in the concept of methodology is associated with practice. The methodological basis was also the philosophical teachings of Eastern thinkers on the formation of personality, moral views, universal and national values, best practices in pedagogy and psychology, the works of the President of the Republic of Uzbekistan Sh.M.Mirziyoev and many monographs. In addition, decisions, decrees and orders, normative documents on the importance of the social environment in the solution of the problem of educational psychology (here, social institutions are considered) also served as the main source of scientific research.

The research is based on the following methods:

- Scientific, psychological and pedagogical analysis of scientific, philosophical, psychological and pedagogical, historical literature, teaching aids on the research topic:

- Organization of interviews and surveys among respondents on the research topic:

- Mathematical-statistical analysis and generalization of research results.

The development of chemistry teaching methods in pedagogical institutes is based on scientific and 
pedagogical problems, the concepts of social environment, social institution are explained, the history of their development is studied, the criteria determining the level of development are defined and the factors are scientifically systematized. Based on the results of the study, scientific-psychological and methodological recommendations for the development of methods of teaching chemistry in pedagogical institutes will increase the educational effectiveness of social influences on the mental development of students. The ideas put forward in the research work are used as a program in educational work among them and serve as an important guide in the development of the mechanism of youth activities.

The recommendations and conclusions developed as a result of this research can be used in the development of programs of social institutions at the district, regional, city and even national levels, and in the implementation of our recommendations in the work with young people in cities and districts, neighborhoods, enterprises and universities can give its effective results.

1) The impact of the development of methods of teaching chemistry in the system of higher education on the quality of training of future competent specialists is determined.

2) Taking into account the developed didactic materials, effective proposals will be developed to improve the process of teaching chemistry in higher education institutions;

3) The essence of the concept of "cognitive competence", the theory of the competent approach is enriched as a result of a comprehensive study of the laws;

4) Didactic tools and methods that activate the process of developing the methodology of teaching chemistry in higher education;

5) Productive conditions for teaching chemistry are determined by giving developmental tasks based on a combination of fundamental, cultural, historical knowledge, which includes all the components of the methodological system, enriching the system of chemical knowledge and skills of students, the general culture.

The practical significance of the work is as follows:

1) The methodical organization of the integrated process of development of methods of teaching chemistry was proposed;

2) The structure and objectives of the chemistry course will be revised;

3) A research manual will be developed, which will include a historical experiment, integrated special courses, electives, print media;

4) Combined forms of training in the context of institutions that increase the effectiveness of the "student-specialist" interaction are proposed;

5) Software-methodical software is developed, educational-methodical complex in chemistry, monographs, recommendations, methodical instructions, videos, programs are prepared which help to achieve the purpose of this research;

6) Criteria characteristics of the process of development of methods of teaching chemistry were identified (mental outlook, intellectual knowledge, way of thinking).

Reliability and accuracy of research results depends on the initial methodological positions, the unity of methods of pedagogical research in accordance with the object and subject, purpose, objectives; consistency and interdependence of results at different stages of the study; validity and non-contradiction of conclusions; provides effective results of experimental work.

\section{Conclusion}

Implementation of research results into practice. Scientific conclusions and results of the research are carried out during the period of pedagogical and educational practice of students of chemistry at the Faculty of Natural Sciences of Navoi State Pedagogical Institute, as well as at various seminars and meetings held at the department.

The following cases are provided for protection:

- The essence of the development of methods of teaching chemistry as a psychological problem in the activities of pedagogical institutes, its components, modern requirements to it, the direction of the formation of methodological knowledge and skills in young people.

- The content of local issues in the development of methods of teaching chemistry;

- The creation of a socio-educational environment in the development of methods of teaching chemistry, the formation of personality, factors of organization of social activity, psychological and pedagogical conditions;

- The content, form, methods and tools for the development of methods of teaching chemistry;

- Methodical recommendations on the formation of socio-psychological aspects of the formation of methodological knowledge of students through the social environment and the formation of behavior and habits.

\section{REFERENCES:}

1. Ishmukhamedov R.J. Ways to increase the effectiveness of education through innovative technologies. 2004, P 45.

2. Dustmurodov T. Chemistry. A collection of problematic lecture texts. 2004, PP 3-6.

3. Khatamova M.S. Proceedings of the XII scientific-practical conference of gifted masters and students on "Innovations in education: scientific-theoretical approaches and experiments." 2013, P 244. 
4. Usmonova L.M. Pedagogical and psychological bases of raising the system of continuing education to a new level of quality. 2014. P 155

5. Usmonova L.M. Proceedings of the Regional Scientific Theoretical Conference on Innovative Technologies in the Teaching of Exact and Natural Sciences. 2014. - P 176. 